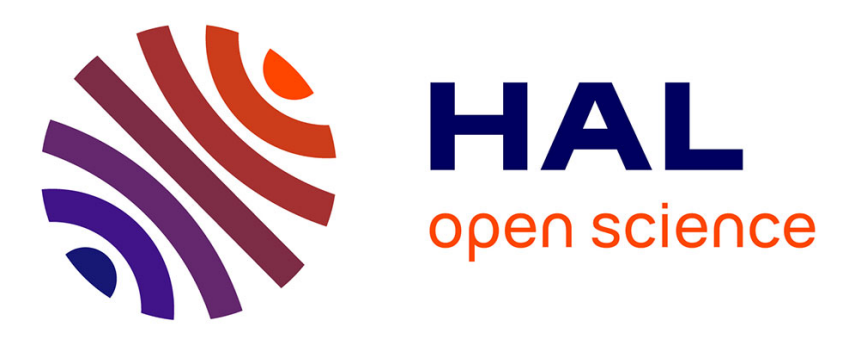

\title{
Ion beam machining of niobium weakly superconducting microbridges
}

\author{
R. Adde, P. Crozat, S. Gourrier, G. Vernet, M. Bernheim, D. Zenatti
}

\section{To cite this version:}

R. Adde, P. Crozat, S. Gourrier, G. Vernet, M. Bernheim, et al.. Ion beam machining of niobium weakly superconducting microbridges. Revue de Physique Appliquée, 1974, 9 (1), pp.179-181. 10.1051/rphysap:0197400901017900 . jpa-00243733

\section{HAL Id: jpa-00243733 https://hal.science/jpa-00243733}

Submitted on 1 Jan 1974

HAL is a multi-disciplinary open access archive for the deposit and dissemination of scientific research documents, whether they are published or not. The documents may come from teaching and research institutions in France or abroad, or from public or private research centers.
L'archive ouverte pluridisciplinaire HAL, est destinée au dépôt et à la diffusion de documents scientifiques de niveau recherche, publiés ou non, émanant des établissements d'enseignement et de recherche français ou étrangers, des laboratoires publics ou privés. 


\title{
ION BEAM MACHINING OF NIOBIUM WEAKLY SUPERCONDUCTING MICROBRIDGES
}

\author{
R. ADDE, P. CROZAT, S. GOURRIER, G. VERNET \\ Institut d'Electronique Fondamentale, Laboratoire associé au CNRS \\ Bâtiment 220, Université Paris XI, 91405 Orsay, France \\ and M. BERNHEIM \\ Laboratoire de Physique des Solides \\ Bâtiment 510, Université Paris XI, 91405 Orsay, France \\ and D. ZENATTI, LETI-DINR \\ Centre d'Etudes Nucléaires, Cedex 85, 38041 Grenoble, France
}

\begin{abstract}
Résumé. - On présente une technique reproductible de fabrication de microponts supraconducteurs applicable aux supraconducteurs «durs» $(\mathrm{Ta}, \mathrm{V}, \mathrm{Nb})$ par bombardement ionique. L'usinage des microponts est obtenu globalement en formant sur un fil mince supraconducteur une image ionique réduite représentant la structure à usiner. Les propriétés de microponts Josephson en niobium sont ensuite décrites : température critique, résistance normale, caractéristique $(I-V)$, action d'un champ magnétique continu et d'un champ hyperfréquence.
\end{abstract}

Abstract. - Superconducting microbridges of hard superconductors can be realized reproducibly using an ion bombardment technique. The micromachining is obtained directly by focussing onto the superconducting film a reduced ionic image which represents the structure to be machined. We describe and discuss the superconducting properties of niobium Josephson microbridges fabricated using this technique : critical temperature, normal resistance, $I-V$ characteristic, dc magnetic field effect and microwave field effect. Microbridges with an operating temperature of $4.2 \mathrm{~K}$ have been realized.

By forming the reduced image of a model on a thin superconducting film, by means of an ion optical system, film openings corresponding to the transparent regions of the model are machined. Thus a positive replica of the model is fashioned in miniature on the thin film.

The application of this method to realize microbridges has been described recently [1] and we have

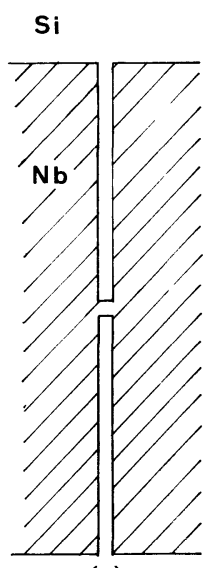

(a)

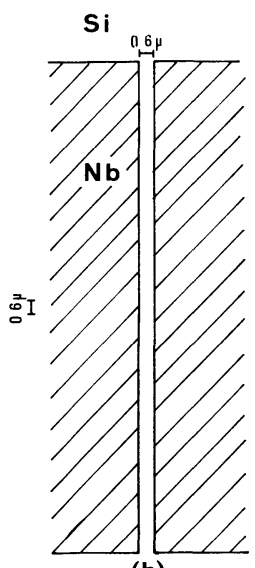

(b)

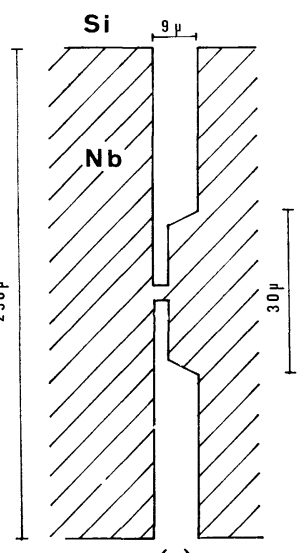

(c)
FIG. 1. - Representation of a bridge (a) or a slit (b) obtained by machining a $500 \AA$ thick niobium film. A new type of model designed to obtain a greater normal resistance of the slit is shown in figure $1 c$. studied the properties of $0.6 \times 0.6 \mu$ bridges realized with $500 \AA$ thick niobium films (Fig. 1a). The ionic bombardment backsputters all the metal along a narrow slit except in the central region corresponding to the microbridge.

1. Modifications of the superconducting properties of the $\mathrm{Nb}$ films by the ionic bombardment. - In view of the complexity of the first obtained results and in order to understand the ionic bombardment effects, we have realized, in a similar way as the microbridges, slits $0.6 \mu$ wide (Fig. 1b) bombarded under the same conditions and we have compared their properties.

Their respective variations of $T_{\mathrm{c}}$ versus the total number of ions falling on the sample are represented on figure 2.

For slits of $0.6 \mu, T_{\mathrm{c}}$ drops quite rapidly down to 2.5 to $3 \mathrm{~K}$ and then decreases very slowly. For bridges (upper curve) $T_{\mathrm{c}}$ is also decreasing in this case, but much slower. The origin of this drop of $T_{\mathrm{c}}$ is probably in a pollution of the bridge due to the aberrations of the ionic optics. This effects, which would be a drawback in other experiments is taken here as an advantage, as we control in this way the bridge critical temperature, and we are thus able to realized bridges with high $T_{\mathrm{c}}$ film $(\sim 8.5 \mathrm{~K})$, with a medium $T_{\mathrm{c}}$ of 


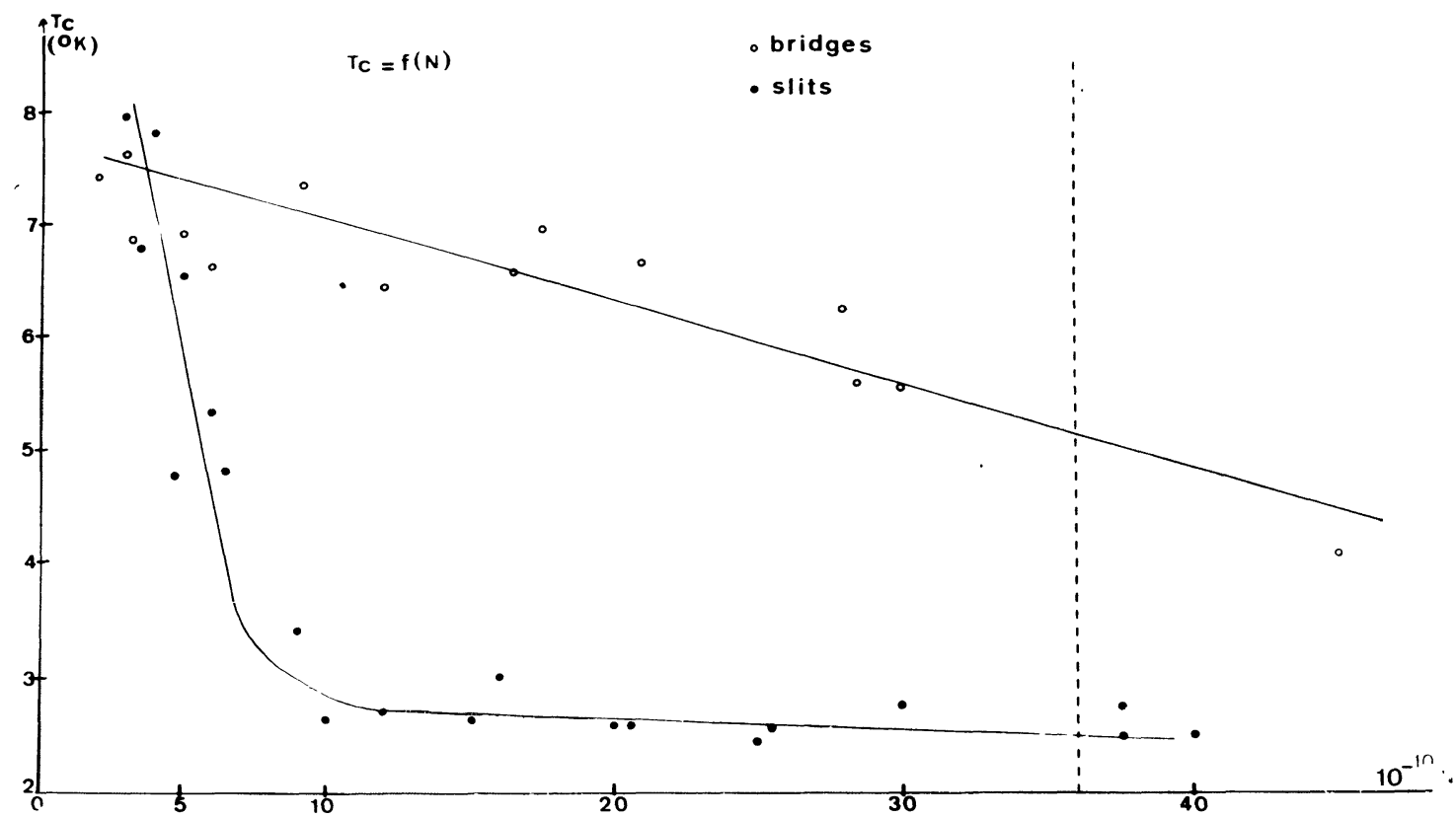

FIG. 2. - Variations of $T_{\mathrm{c}}$ versus the total number of ions falling on the sample.

the bridges ( $\sim 5$ to $6 \mathrm{~K}$ ) and an operational temperature of $4.2 \mathrm{~K}$.

As the critical temperature of the slit is lower than that of the corresponding bridge, the latter at its operating temperature is shunted by the normal resistance of the slit, which is generally found equal to a few tenths of an ohm. This is a drawback for detection purposes, and we realize now structures with a slit of increasing width (Fig. 1c) and we have already obtained a normal resistance of $1.2 \Omega$. Thus we think that the shunting effect will be decreased. We cannot say anything definite yet about the normal resistance of the bridges because of this shunting effect.

The dashed line on figure 2 shows the theoretical limit at which the machining should be total.

The residual superconductivity beyond this line is probably due to some proximity effect between both sides of the film either because all the $\mathrm{Nb}$ atoms are not sputtered or by a mechanism involving the fraction of $\mathrm{Nb}$ atoms implanted in the silicon substrate, by the recoil energy. This is corroborated (Fig. 3) by the exponential variation of $I_{c}$ of a slit versus $T$ in the vicinity of the $T_{\mathrm{c}}$ (slit), which may be compared to what has been observed in $\mathrm{Nb}-\mathrm{Ta}$ proximity effect bridges by Notarys and Mercereau [2].

2. Critical current variations with $T_{\text {c }}-$ In general they can be fitted with a theoretical curve of the form

$$
I_{\mathrm{c}}(t) \sim(1-t)^{\alpha}
$$

where

$$
t=\frac{T}{T_{\mathrm{c}}} \text { and } 1.5<\alpha<2 .
$$

A variation of $I_{c}(t) \sim(1-t)^{3 / 2}$ is shown on figure 4 where $I_{\mathrm{c}}^{2 / 3}$ is plotted versus temperature.

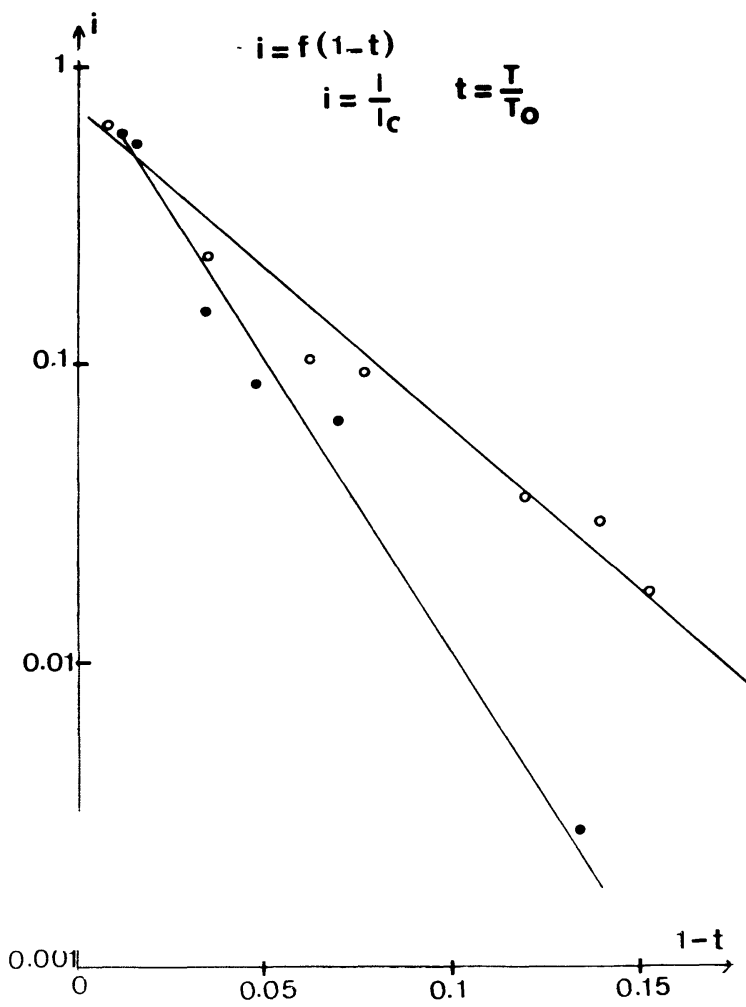

FIG. 3. - Exponential variation of $I_{\mathrm{c}}$ of a slit versus $T$ near $T_{\mathrm{c}}$ of the slit.

This type of variation has been observed previously [3] for long Sn bridges (a few $\mu$ with a $\xi$ of 2 000-3 $000 \AA$ ) and more recently for $\mathrm{Nb}$-Ta bridges with a length comparable to ours [2]. They observed this effect only at low temperatures since in the vicinity of $T_{\mathrm{c}}$ their behavior is that of proximity effect bridges. We believe that our bridges do not show any proximity effect near $T_{\mathrm{c}}$ (bridge), because of 


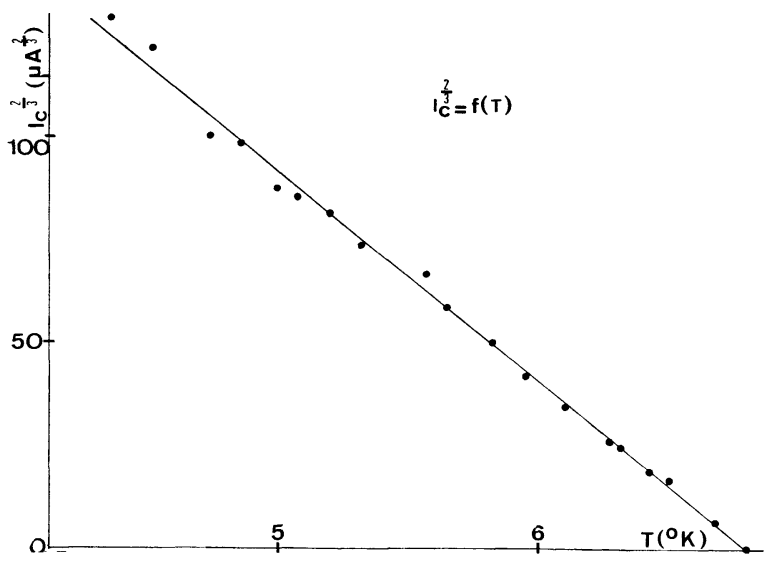

FIG. 4. - Variation of $I_{\mathbf{c}}^{2 / 3}$ versus $T$ for a bridge.

their very small width compared with that of proximity effect bridges.

3. I-V characteristic. - For bridges with low critical currents an excess current over the normal state value has been observed even at large voltages confirming the phase slip bridge model [4]. But we found difficult to observe it very precisely as the measure is thwarted by heating effects at large currents. Figure 5 shows the effect of $9 \mathrm{GHz}$ radiation on the $I-V$ characteristic for a $\mathrm{Nb}$ bridge operating at $4.2 \mathrm{~K}$. As the bridge $T_{\mathrm{c}}$ is about $6.5 \mathrm{~K}$ these results are the experimental proof that properly designed super-

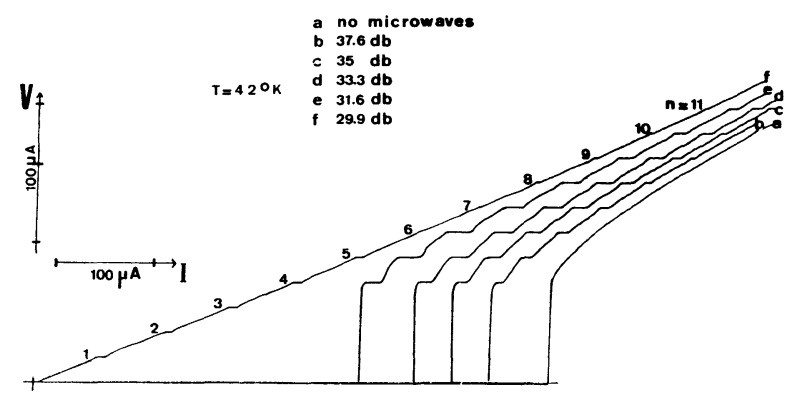

Fig. 5. - I-V characteristics of a $\mathrm{Nb}$ bridge as a function of $9 \mathrm{GHz}$ power at $4.2 \mathrm{~K}$.

conducting bridges are sensitive to microwaves relatively far from their $T_{\mathrm{c}}$.

The 10th step is still very well seen. No periodicity of any step or enhancement of the critical current with increasing microwave power was observed. The first 3 steps cannot always be seen here as the $I-V$ curve shows some hysteresis because of the rather large critical current.

Finally, what differentiates mostly our bridges from previously published results is their small sensitivity in an external dc magnetic field normal to the film plane due to their small transverse dimensions [2]. Figure 6 shows the decrease of $I_{c}$ of a bridge versus magnetic field. The first minimum corresponds to $B \sim 500 \mathrm{G}$. A rough modulation of $I_{\mathrm{c}}$ is also observed.

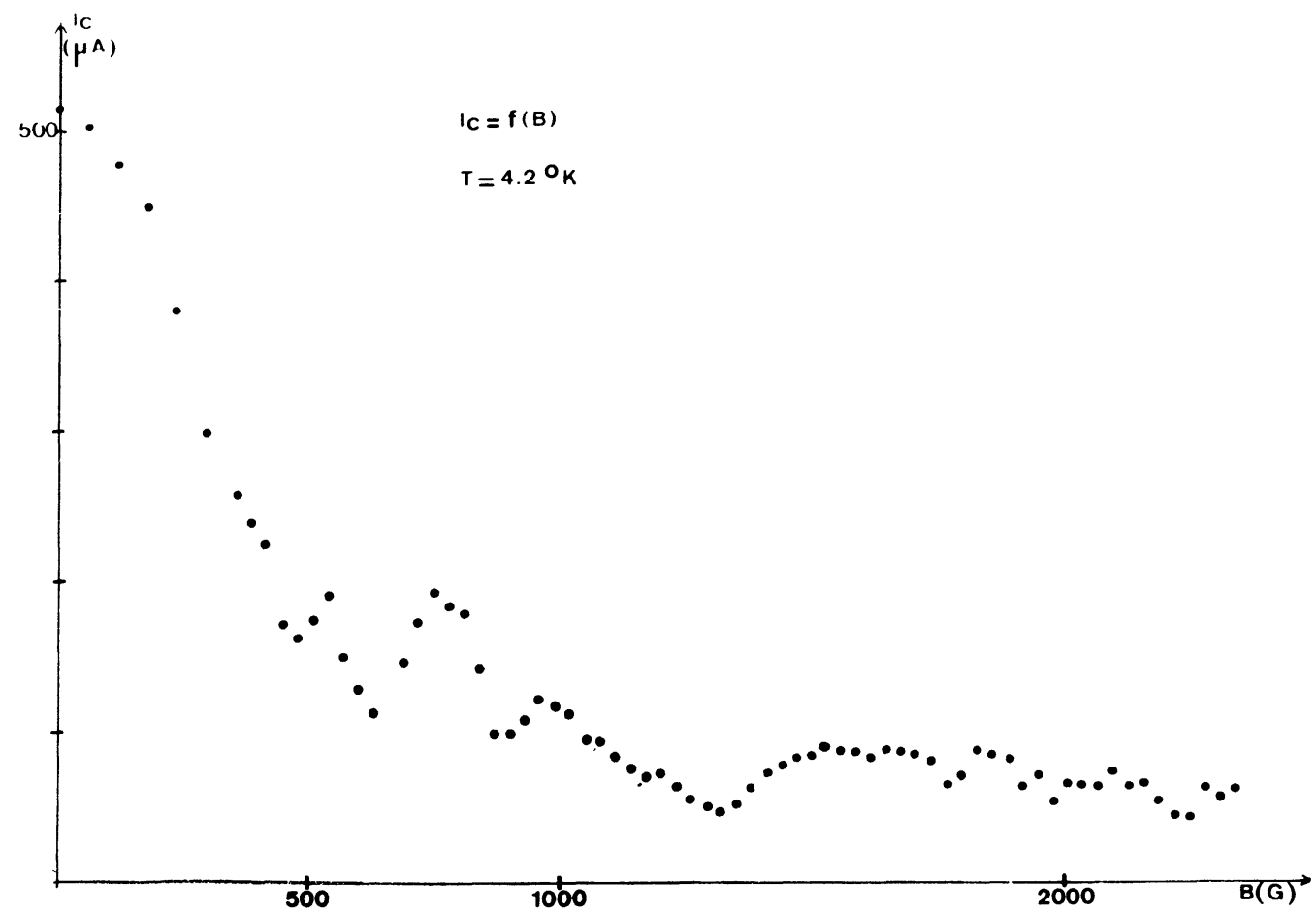

FIG. 6. - Variation of the critical current of a bridge versus magnetic field normal to the film plane.

\section{References}

[1] Adde, R., Crozat, P., Gourrier, S., Vernet, G., Bernheim, M., ZenatTI, D., Revue Phys. Appl. 8 (1973) 455.

[2] Notarys, H. A. and Mercereau, J. E., J. Appl. Phys. 44 (1973).
[3] DU Song, Y., Thesis, Ph-D., Berkeley (novembre 1971).

[4] Rieger, T. J., Scalapino, D. J. and Mercereau, J. E., Phys. Rev. B 6 (1972). 